\title{
Fatty acid characterization of indigenous cyanobacterial strains isolated from five hot springs in indonesia
}

\author{
Nining Betawati Prihantini ${ }^{1, *}$, Sri Handayani ${ }^{2}$, Wellyzar Sjamsuridzal ${ }^{1,3},{\text { Akira } \text { Yokota }^{4} \text {, and Nasruddin }}^{5}$ \\ ${ }^{1}$ Department of Biology, Faculty of Mathematics and Natural Sciences, Universitas Indonesia, Depok 16424, Indonesia \\ ${ }^{2}$ Department of Chemistry, Faculty of Mathematics and Natural Sciences, Universitas Indonesia, Depok 16424, Indonesia \\ ${ }^{3}$ Center of Excellence for Indigenous Biological Resources-Genome Studies, Faculty of Mathematics and Natural Sciences, \\ Universitas Indonesia, Depok 16424, Indonesia \\ ${ }^{4}$ Graduate School of Agricultural Sciences, Faculty of Agriculture, Tohoku University, Japan \\ ${ }^{5}$ Department of Mechanical Engineering, Faculty of Engineering, Universitas Indonesia, Depok 16424, Indonesia
}

\begin{abstract}
Cyanobacteria have been known to produce lipids that are potential for biodiesel. Cyanobacteria isolated from Indonesia are called Indonesia indigenous cyanobacteria. This study was conducted to determine the characterization of fatty acids contained in cyanobacteria originating from Indonesia which were isolated from 5 hot springs in Indonesia. For some 29 strains of cyanobacteria consisting of 8 genera have performed the analysis of fatty acids (FA) by extraction method via protocol in SHERLOCK Microbial Identification (Midi) System version 4.0, 2001 MIDI, Inc. The resulting data is as follows. All strains of 8 genera (Synechococcus, Merismopedia, Thermosynechococcus, Stanieria, Leptolyngbia, Westiellopsis, Mastigocladus, and Nostoc) have saturated fatty acids (SFA) and unsaturated fatty acids (MUFA and PUFA). The content of saturated fatty acids ranged from 27.77 to $50.56 \%$, while the content of unsaturated fatty acids ranged from 7.58 to $63.31 \%$. All strains have SFA Palmitic acid (16:00) which ranges from 23.23 to $42.64 \%$. Meanwhile, unsaturated fatty acids Palmitoleic acid (16:1 wc7) are owned by almost all strains except Westiellopsis which range from 1.75 to $51.78 \%$. Content of unsaturated fatty acids Oleic acid (18: w9c) ranges from 1.43 to $35.78 \%$ mainly in Leptolyngbia, Westiellopsis, and Mastigocladus. All strains have MUFA ranging from 7.58 to $63.31 \%$, whereas PUFA is only owned by filamentous strains (Leptolyngbia, Westiellposis, Mastigocladus, and Nostoc). From the results of the research can be seen that 29 strains of cyanobacteria of 8 genera have potential fatty acids as raw materials of biodiesel under certain conditions.
\end{abstract}

\section{Introduction}

Concerns about petroleum supplies, high energy prices, and energy-related environmental security drew much attention to finding renewable biofuels. One renewable biofuel is biodiesel. Biodiesel is a type of liquid fuel in the form of Fatty Acid Methyl Ester (FAME) or methyl ester compound with long fatty acid chain [1]. One of the benefits of biodiesel is environmentally friendly, because it comes from renewable biological raw materials and does not increase $\mathrm{CO}_{2}$ emissions into the atmosphere due to the mechanism of carbon recirculation.

Biodiesel is generally derived from various types of vegetable oils. One of the biodiesel materials comes from microalgae. Microalgae are a group of autotrophic microorganisms that have no organs with apparent functional differences. Microalgae can be an appropriate alternative feedstock for next generation biofuels because certain species are known to contain lipids including high fatty acids in their biomass. Microalgae biomass can be extracted, processed, and refined into transportation fuels using the technology currently available. In addition, the microalgae can reduce the amount of carbon in the air simultaneously, have fast growth rates, allow unused cultivation and unreachable water, their production is not seasonal and can be harvested daily.

Microalgae are categorized into eukaryotic and prokaryotic microalgae. One of the prokaryotic microalgae is cyanobacteria. Cyanobacteria also commonly referred to as Cyanophyta, blue green algae, or Myxophyta [2,3] that have variations of form, i.e. unicellular, filament, or colony. Cyanobacteria as well as other microalgae are also known to produce lipids which can then be extracted and utilized. Some cyanobacteria have been known to produce lipids that are potential for biodiesel, i.e. Spirulina, etc.

In Cyanobacteria, the fatty acid properties of cyanobacteria cells are important for comparing the biochemical diversity of cyanobacteria. So far, the analysis shows members of a unique and varied cyanobacteria group regarding fatty acid composition. As with bacteria, fatty acid composition in cyanobacteria 
can be used as a marker in taxonomy [4, 5, 6]. For example, there is a significant correlation between the complexity of the species morphology and its fatty acid composition [7].

Fatty acid on the entire cell composed of saturated fatty acids (SFA), unsaturated fatty acids (MUFA/monounsaturated FA and PUFA/polyunsaturated FA), branched fatty acids and hydroxy-substituted fatty acids. Saturated fatty acids that are common to the entire cyanobacteria including bacteria is palmitic acid (16:0). Some cyanobacteria have a fatty acid composition as species of bacteria, some of the types of chloroplasts, and some of the type is not yet clear whether in bacteria or in chloroplasts. The fatty acid composition of bacteria is relatively common among unicellular cyanobacteria, whereas polyenoic fatty acid is most common filamentous cyanobacteria [8].

Cyanobacteria are microorganisms that can live anywhere or commonly called cosmopolitan microorganisms. Indonesia as one tropical country that always has a warm climate all year long cause often experiences blooming Cyanobacteria in freshwater. The study of microalgae community structures in some lakes and rivers in Indonesia indicates that many strains of Cyanobacteria appear to dominate certain waters. Some research has shown that Cyanobacteria is easily found in UI waters $[9,10,11]$ or some waters of lakes and rivers in the Jakarta area $[12,11,13]$, and at sources hot water in Indonesia $[14,15,16]$. Cyanobacteria found and isolated from Indonesia are called Indonesian indigenous cyanobacteria.

For the purposes of the use of cyanobacteria for biodiesel, cyanobacteria which may be used should be cultured cyanobacteria and can be grown in large quantities. In addition, strain characteristics also determine successful utilization. Optimal and stable strains can be used in observing genetic diversity, toxicity, and other benefits and applications.

Before being used as a biodiesel agent, the fatty acid content of cyanobacteria strains needs to be analyzed. Screening of fatty acids is needed to know which type of fatty acids are contained in these strains. This study was conducted to determine the characterization of fatty acids contained in cyanobacteria originating from Indonesia. The study was conducted on cyanobacteria isolated from hot springs in Indonesia.

\section{Materials and Methods}

\subsection{Microorganisms and Growth Medium}

Cyanobacteria strains were isolated from hot springs and grown on a medium suitable for the growth of each strain of cyanobacteria. The Cyanobacteria strain used in this study were cyanobacteria strains derived from 5 hot springs in West Java, Indonesia. Fatty Acid characterization performed on 29 strains of Indonesian hot springs cyanobacteria. Hot springs in Indonesia, namely Ciseeng, Mount Pancar, Rawa Danau Banten, Ciater, and Maribaya. Meanwhile, the growth medium used were CT (Cyanobacteria TAPs), MA (Microcystis Aeruginosa Medium), BG-11 (Blue Green no. 11) [17], and BBM (Bold Basal Medium) [18].

\subsection{Research places}

Researches were conducted at the Laboratory of Plant Taxonomy, Department of Biology, FMIPA, UI, and Laboratory Center of Excellence Indigenous Biological Resources Genome Studies (CoE IBR - GS) FMIPA UI. Maintenance of hot spring cyanobacteria strains was carried out in Algae Culture Room Laboratory of Plant Taxonomy, Department of Biology, FMIPA UI.

\subsection{Culturing, preparing of starter cultures, and harvesting of cultures}

Propagation of culture was begun with the inoculation of $15 \mathrm{~mL}$ of culture from the culture of work into Erlenmeyer flask containing $150 \mathrm{~mL}$ of medium. Work was done in aseptic technique. Further cultures were incubated in the rack culture. The intensity of light given was $3000-5000$ lux, with photoperiodicity $12 \mathrm{~L} / 12 \mathrm{D}$ regulated by a timer. Incubation temperature which used were $20 \pm 5{ }^{\circ} \mathrm{C} ; 30 \pm 5{ }^{\circ} \mathrm{C}$; and $50 \pm 5{ }^{\circ} \mathrm{C}$. Cyanobacteria cultures in test tubes and Erlenmeyer flasks were shown at Fig.1.

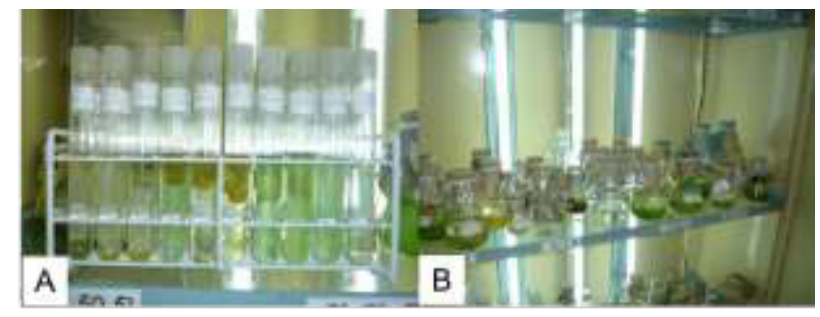

Fig. 1. Culture of cyanobacteria: A. in the test tube as a culture collection, B. in Erlenmeyer flasks for fatty acid analysis

\subsection{Fatty Acid Characterization}

\subsubsection{Extraction of Fatty Acid}

There were five (5) steps for extracting the samples. The steps were harvesting, saponification, methylation, extraction, and washing. Besides harvesting procedure, other steps procedure was done by protocols in SHERLOCK Microbial Identification (Midi) System version 4.0, 2001 MIDI, Inc. The extract preparation procedures were shown at Fig.2.

Harvesting was done when the cyanobacteria cultures reached 20 days old or already exist in the early stationary phase. Culture was put into centrifuge tubes, and then centrifuged at $4500 \mathrm{rpm}$ for $20 \mathrm{~min}$ (modified [19]). Centrifugation process produced pellets (wet biomass) and supernatant. Wet biomass and the supernatant obtained was frozen in a freezer at a temperature of $4{ }^{\circ} \mathrm{C}$. 


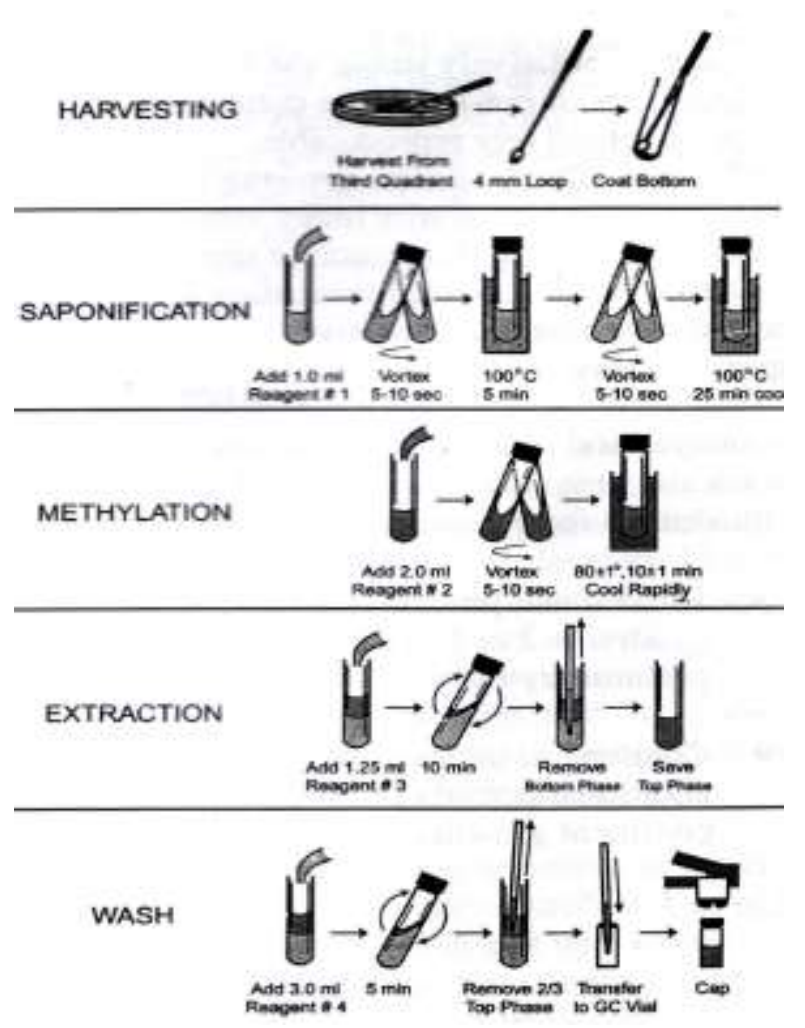

Fig. 2. The fatty acid extract preparation procedures

After harvesting, the cells were saponified. There were 3 kinds of chemical compounds for saponify the cells, i.e. sodium hydroxide (certified ACS), methanol (HPLC grade), and deionized distilled water. Those compounds were mixed $(150 \mathrm{~mL}$ deionized distilled water, $150 \mathrm{~mL}$ methanol, 45 gram sodium hydroxide/ $\mathrm{NaOH}$ ), and namely reagent 1 (the methalonic base). A strong methanolic base combined with heat kills and lysis the cells. Fatty acids were hydrolyzed form the cell lipids and were converted to their sodium salts (Midi: 18). Samples $(5 \pm 10 \mathrm{mg}$ cells $)$ were transferred into a clean, dry $13 \mathrm{~mm} \times 100 \mathrm{~mm}$ screw cap culture tube. Reagent $1(1.0 \pm 0.1 \mathrm{~mL})$ was pipetted in to each of the culture tubes in the batch, and each tube was sealed tightly with a clean Teflon-lined screw cap. The tubes were vortexed for 5-10 seconds. The batched samples tubes rack was placed into a boiling or circulating water bath at $95{ }^{\circ} \mathrm{C}-100{ }^{\circ} \mathrm{C}$ for 5 minutes. After five (5) minutes, the tubes were removed from the boiling water, and cooling the tubes slightly. Then again, the tubes were vortexed for 5-10 seconds and then returned to the water bath for additional 25 minutes.

Next step was methylation. There were 2 kinds of chemical compounds for methylation, i.e. $6.00 \mathrm{~N}$ hydrochloric Acid $(\mathrm{HCl})$ and methanol (HPLC grade). The mixing of two chemicals was called reagents 2 or the methylation reagent $(325 \mathrm{~mL} \mathrm{HCl}$ and $275 \mathrm{~mL}$ methanol). Methylation converts the fatty acids (as sodium salts) to fatty acid methyl esters, which increases the volatility of the fatty acids for the Gas Chromatography (GC) analysis. The cap of tube from saponification steps was opened in the batch, the tubes then were added with $2.0 \pm 0.1 \mathrm{~mL}$ of reagent 2 to each tube. Each tube was sealed tightly with a clean Teflon- lined screw cap, and the tubes were vortexed for 5-10 seconds. Because of an excess of reagents, a granular precipitate (salt) may form, and proceed with the following. The tubes were heated in an $80 \pm 1{ }^{\circ} \mathrm{C}$ water bath for $10 \pm 1$ minute. Then, the tubes were removed and quickly cool to room temperature by placing tubes in a tray of cold tap water. Ice-cold water was not necessary. The tubes were shaken to speed the cooling process.

Extraction was done using extraction solvent that comprises 2 kinds of chemical compounds, i.e. hexane (HPLC grade) and methyl tert-butyl ether/MTBE (HPLC grade). MTBE was added to the hexane and stirred well. Fatty acid methyl esters were removed from acidic aqueous phase and transferred to an organic phase with a liquid-liquid extraction procedure. The cap of tube from methylation steps was opened. Each tube was then added with $2.0 \pm 0.1 \mathrm{~mL}$ of reagent 3 . Each tube was sealed tightly with a clean Teflon-lined screw cap. Batch of tubes in a laboratory rotator was placed and gently mix end-over-end for 10 minutes. The cap of tube was opened again. The aqueous (lower) phase was removed and discarded using a clean Pasteur pipette for each sample.

Final step was called Base Wash. Base wash was done using reagent 4 which were included sodium hydroxide $/ \mathrm{NaOH}$ (certified ACS) and deionized distilled water. Sodium hydroxide $(\mathrm{NaOH})$ was added to stirring water until the pellets were dissolved. A dilute base solution was added to the sample preparation tubes to remove free fatty acids and residual reagents from the organic extract. Residual reagents will damage the chromatographic system, resulting in tailing and loss of the hydroxy fatty acid methyl esters.

Each tube then was added with $3.0 \pm 0.1 \mathrm{~mL}$ of reagent 4 . Each tube was sealed tightly with a clean Teflon-lined screw cap. The tubes were rotated gently end-over-end for 5 minutes. Brief centrifugation (3 minutes at $2000 \mathrm{rpm}$ ) was recommended to clarify the interface between the phases when an emulsion was present.

\subsubsection{Fatty Acid Analysis}

Furthermore, the upper solvent phase was removed and placed in a sample vial suitable for the automatic sampler mounted on the gas chromatograph. The extract was transferred to sample Vial and analyzing of samples according to the procedure of SHERLOCK MIS (Microbial Identification System) version 4, MIDI, Inc.

\section{Results and Discussion}

\subsection{The growth of cyanobacteria strains}

Twenty-nine (29) strains were characterized as cellular fatty acids. The process of analysis of fatty acids (FAs) was very dependent on the ability to grow and the speed of growth of cyanobacteria strains. Strains were analyzed and grouped into three (3) groups. The first group was strains that grew fast enough or normal, 
which entered a period of peak growth of about 20 days (20 days of age culture). The second group were strains that had slow growth (30 to 40 days), while the third group were the strains that had very slow growth (more than 40 days). The first group (fast enough/normal growth) consists of strains of Synechococcus (HS-1, HS7, HS-8, HS-13, HS-18), Leptolyngbia (HS-16, HS-30A, HS-31A, HS-33, HS-40, HS-40C, HS-41, HS-42), Nostoc (HS-5 strain, HS-20), Mastigocladus (strain HS40A, HS-46), and Westiellopsis HS-10. The second group (slow growth) consists of strains of Synechococcus HS-9, Thermosynechococcus HS-17, Leptolyngbia (HS-27, HS-28, HS-49), and Stanieria HS35. Meanwhile, the third group (very slow growth) consists of strains of Merismopedia HS-6 and Stanieria HS-29. The amount of biomass that entered the harvest and was sufficient for the analysis of fatty acids was 50 mg wet weight.

\subsection{Fatty Acids of cyanobacteria strains}

The results of the analysis of fatty acid of 29 strains of cyanobacteria (i.e., the identification based on morphological characters and $16 \mathrm{~S}$ rRNA) was as follows. Fatty acids which observed from 29 strains were 7 saturated fatty acid (12:0, 14:0, 16:0, 18:0, 17:0 CYCLO; 19:0 CYCLO w8c; and 19:0 CYCLO w10c), 15 unsaturated fatty acids (13:1 AT12-13; 14:1 w5c; 16:1 w1c; 16:1 w5c; 16:1 w7c; 16:1 w7c alcohol; 16:1 w9c; 17:1 w8c;18: w6c 1;18: 1 w7c;11 methyl 18:1 w7c; $18: 1 \mathrm{w} 9 \mathrm{c} ; 18: 2 \mathrm{w6,9c} ; 20: 4 \mathrm{w} 6,9,12,15 \mathrm{c}$; and $20: 2$ w6,9c), 19 branched Fatty acid (11:0 ISO $3 \mathrm{OH} ; 13: 0$ ISO; 14:0 ISO; 14:0 ANTEISO; 15:0 ISO; 15:0 ANTEISO; 15:0 ISO 2OH; 16:0 ISO; 16:1 ISO I ; 16:0 ANTEISO; 16:0 10 methyl; 16:0 ISO 3OH; 17: 0 ANTEISO; 17: 010 methyl; ISO 17:1 w7c; ISO 17:1 w10c; 17:0 ISO 3OH; 18:0 ISO; and 19:0 10 methyl), and 9 Hydroxy-substituted Fatty Acid (13:0 2OH, 14:0 2OH; 14:0 3OH; 15:0 2OH; 16:0 2OH; 16:0 3OH, 17:0 2OH; 18:0 2OH; and 18:0 3OH). Table 1a, Table 1b, Table 1c., and Table 2 shows the analysis data of fatty acids that owned by more than 2 strains. Tables were arranged in order of the genus, i.e. Synechococcus, Merismopedia, Thermosynechococcus, Stanieria, Leptolyngbia, Westiellopsis, Mastigocladus, and Nostoc.

The results of fatty acid analysis showed as follows (Table 1a). The whole strains had saturated fatty acids 16:0 [hexadecanoic acid/Palmitic acid/ $\left.\mathrm{CH}_{3}\left(\mathrm{CH}_{2}\right)_{14} \mathrm{COOH}\right]$ ranged from 23.23 to $42.64 \%$. Most of the strains had monounsaturated fatty acids $16: 1 \mathrm{w} 7 \mathrm{c}$ [(Z)-hexadec-9-enoic acid, n-7/palmitoleic acid/ $\left.\mathrm{C}_{15} \mathrm{H}_{29} \mathrm{CO}_{2} \mathrm{H}\right]$ ranged from 1.75 to $51.78 \% ; 18: 1 \mathrm{w} 7 \mathrm{c}[(\mathrm{Z})-$ octadec-11-enoic acid, n-7/Vaccenic acid $\left./ \mathrm{C}_{17} \mathrm{H}_{33} \mathrm{CO}_{2} \mathrm{H}\right]$ ranged from 1.30 to $15.82 \%$; and $18: 1 \mathrm{w} 9 \mathrm{c}$ [(Z) -octadec9-enoic acid, n-9/Oleic acid/ $\left.\mathrm{C}_{17} \mathrm{H}_{33} \mathrm{CO}_{2} \mathrm{H}\right]$ ranged from 1.43 to $35.78 \%$. In this research, Westiellopsis strain HS-10 had no unsaturated fatty acids 16:1w7c (palmitoleic acid), while strains Stanieria HS-29 and Leptolyngbia HS-49 had not unsaturated fatty acids 18:1w7c (Vaccenic acid). In addition, monounsaturated fatty acids 18:1w9c[(Z)-octadec-9-enoic acid, n-9/Oleic acid/ $\left.\mathrm{C}_{17} \mathrm{H}_{33} \mathrm{CO}_{2} \mathrm{H}\right]$ ranged from 1.43 to $35.78 \%$ owned by most strains, especially strains Leptolyngbia (HS- 16, HS-27, HS-28, HS-30A, HS-31A, HS-33, HS-34, HS36, HS-39, HS-40B, HS-40C, HS-41, HS-42, HS-49), Westiellopsis (HS-10), and Mastigocladus (HS-40A, HS46). The polyunsaturated fatty acids/ Di-unsaturated 18:2w6,9c[(6Z,9z)-octadec-6,9-dienoic acid, n6/Linoleic acid/ $\left.\mathrm{C}_{17} \mathrm{H}_{33} \mathrm{CO}_{2} \mathrm{H}\right]$ were owned by the majority of genus Leptolyngbya (HS-28, HS-30A, HS31 A, HS-33, HS-36, HS-39, HS-40B, HS-40C, HS-42, HS-49), the genus Westiellopsis (HS-10), the genus Mastigocladus (HS-40A), and the genus Nostoc (HS-5, HS-20) ranged from 2.56 to $29.62 \%$.

Other types of fatty acid such as branched fatty acid (Table 1b) and substituted hydroxy fatty acid (Table 1c) were shown as follows. Branched fatty acid analysis results showed that most of the strains had a 17:0 10 methyl [10-Methylheptadecanoic acid] ranging from $2: 14$ to $7: 10 \%$. Meanwhile, substituted hydroxy fatty acid varied and not all had that fatty acid. The whole strain of Synechococcus (HS-1, HS-7, HS-8, HS-9, HS13, HS-18), strain Merismopedia (HS-6), and strain Thermosynechococcus (HS-17) had branched fatty acids 16:0 3OH (3-Hydroxyhexadecanoic acid) ranged from 2.53 to $7.75 \%$, as well as Nostoc strains had that fatty acids in the range of $2: 36$ to $4: 33 \%$.

From the overall analysis of the fatty acids obtained, results illustrated that the group of unicellular cyanobacteria strains (Synechococcus, Merismopedia, Thermosynechococcus and Stanieria) had a total polyunsaturated (PUPA) lower $(0 \%)$ than in most groups of filamentous cyanobacteria (Leptolyngbia, Westiellopsis, Mastigocladus and Nostoc) (Table 2). Except in Synechococcus HS-7, the total PUPA strain was 7.24\%, as Synechococcus HS-7 had an 18:2 w6,9c /linoleic acid (2.56\%); 20:4w6,9,12,15c (Eicosanoic/arachidonic acid $\left.\mathrm{C}_{20} \mathrm{H}_{40} \mathrm{O}_{2}\right)(3.11 \%$ ), and 20:2w6,9c and 20:2 w6c (11z,14Z)-11.14-Eicosadienoic acid Eicosadienoic acid (1.57\%).

In addition to a low total PUPA, all strains of Synechococcus (HS-1, HS-7, HS-8, HS-9, HS-13, HS18) and Merismopedia (HS-6) had a saturated fatty acid 14:0 [Tetradecanoic acid/Myristic acid/CH3 (CH2) $12 \mathrm{COOH}$ ] ranged from 7.16 to $23.54 \%$. Meanwhile other strains (Stanieria, Leptolyngbya, Westiellopsis, Mastigocladus, and Nostoc) had saturated fatty acids 14:0 was lower than Synechococcus strains and Merismopedia group (0-4.09\%). 
Table 1a. The results of the analysis of fatty acids (FAs) of the cyanobacteria strains (saturated and unsaturated fatty acid)

\begin{tabular}{|c|c|c|c|c|c|c|c|c|c|c|c|c|c|c|c|c|}
\hline \multirow[b]{3}{*}{$\begin{array}{c}\text { Num } \\
\text { ber }\end{array}$} & \multirow[b]{3}{*}{ Genus Name } & \multirow[b]{3}{*}{$\begin{array}{c}\text { Strain } \\
\text { Code }\end{array}$} & \multicolumn{14}{|c|}{ \% Fatty Acids } \\
\hline & & & \multicolumn{6}{|c|}{ Saturated } & \multicolumn{8}{|c|}{ Unsaturated } \\
\hline & & & $12: 00$ & $14: 00$ & $16: 00$ & $18: 00$ & $\begin{array}{c}17: 0 \\
\text { CYCLO }\end{array}$ & $\begin{array}{c}19: 0 \\
\text { CYCLO } \\
\text { w8c } \\
\end{array}$ & $\begin{array}{c}13: 1 \\
\text { AT12- } \\
13 \\
\end{array}$ & $\begin{array}{l}16: 1 \\
w 7 \mathrm{c}\end{array}$ & $\begin{array}{c}\text { 16: } 1 \\
\text { w7c } \\
\text { alcohol }\end{array}$ & $\begin{array}{l}16: 1 \\
\mathrm{w} 9 \mathrm{c}\end{array}$ & $\begin{array}{l}18: 1 \\
w 7 c\end{array}$ & $\begin{array}{c}11 \\
\text { methyl } \\
18: 1 \\
\text { w7c } \\
\end{array}$ & $\begin{array}{l}18: 1 \\
\text { w9c }\end{array}$ & $\begin{array}{r}18: 2 \\
\text { w6,9c } \\
\end{array}$ \\
\hline 1 & Synechococcus & HS-1 & - & 7.16 & 30.03 & 1.94 & & 16 & & 9.61 & 2.74 & & 15.82 & 1.17 & & \\
\hline 2 & Synechococcus & HS-7 & - & 15.73 & 25.72 & 1.59 & & & & 24.38 & & & 5.76 & & 6.98 & 2.56 \\
\hline 3 & Synechococcus & HS-8 & - & 19 & 27 & & & & & 32.39 & & & 4.03 & & & \\
\hline 4 & Synechococcus & HS-9 & - & 20.6 & 23.23 & & & 2.6 & & 9.67 & & & 6.12 & & 1.46 & \\
\hline 5 & Synechococcus & HS-13 & - & 18.22 & 25.98 & & & 1.39 & & 26.78 & 1.33 & & 5.49 & & & \\
\hline 6 & Synechococcus & HS-18 & - & 18.43 & 23.36 & & & 1.72 & 2.53 & 22.44 & & & 3.93 & & & \\
\hline 7 & Merismopedia & HS-6 & - & 23.54 & 23.35 & & & & & 31.13 & & & 2.11 & & & \\
\hline 8 & $\begin{array}{l}\text { Thermo } \\
\text { synechococcus }\end{array}$ & HS-17 & - & & 38.61 & & & & & 22.8 & & 1.49 & 14.2 & & 10.7 & \\
\hline 9 & Stanieria & HS-29 & - & 2.2 & 29.95 & & & & & 51.78 & 1.46 & & & & & \\
\hline 10 & Stanieria & HS-35 & - & 2.38 & 25.73 & & & & 1.84 & 39.71 & 1.52 & & 2.26 & & & \\
\hline 11 & Leptolyngbia & HS-16 & - & & 25 & & 14.27 & & & 23.54 & & & 2.57 & & 1.43 & \\
\hline 12 & Leptolyngbia & HS-27 & - & & 38.61 & & & & & 12.26 & & & 5.2 & & 35.78 & \\
\hline 13 & Leptolyngbia & HS-28 & - & & 37.86 & 1.83 & & & & 9.33 & 2.8 & & 4.29 & & 16.08 & 19 \\
\hline 14 & Leptolyngbia & $\begin{array}{l}\text { HS- } \\
30 \mathrm{~A} \\
\end{array}$ & - & & 37.62 & & & & & 18.87 & 1.84 & & 4.49 & & 10.93 & 16.7 \\
\hline 15 & Leptolyngbia & $\begin{array}{l}\text { HS- } \\
31 \mathrm{~A} \\
\end{array}$ & - & & 37.87 & 2.06 & & & & 9.38 & 2.56 & & 3.12 & & 15.7 & 19.2 \\
\hline 16 & Leptolyngbia & HS-33 & - & & 37.88 & 1.61 & & & & 12.12 & 1.99 & & 4.38 & & 9.94 & 23.5 \\
\hline 17 & Leptolyngbia & HS-34 & - & & 30.93 & 1.88 & & & & 25.69 & & 11.56 & 5.85 & & 9.17 & \\
\hline 18 & Leptolyngbia & HS-36 & - & & 29.6 & 1.71 & & & & 10.7 & 1.83 & & 4.16 & & 23.44 & 9.74 \\
\hline 19 & Leptolyngbia & HS-39 & 1.96 & 2.07 & 35.35 & 3.85 & & & 1.38 & 11.74 & 1.73 & 1.22 & 3.67 & & 14.42 & 15.5 \\
\hline 20 & Leptolyngbia & $\begin{array}{l}\text { HS- } \\
40 B \\
\end{array}$ & - & & 31.1 & 1.98 & & & & 5.45 & & 14.39 & 2.99 & & 25.39 & 6.38 \\
\hline 21 & Leptolyngbia & $\begin{array}{l}\text { HS- } \\
40 \mathrm{C}\end{array}$ & 1.1 & 1.77 & 37.91 & 2.19 & & & & 24.3 & 1.43 & & 4.56 & & 7.68 & 15.3 \\
\hline 22 & Leptolyngbia & HS-41 & - & 1.86 & 34.73 & & & & & 38.84 & 1.3 & & 4.77 & & 8.94 & \\
\hline 23 & Leptolyngbia & HS-42 & - & 1.05 & 28.24 & & & & & 27.48 & 1.24 & & 4.99 & & 8.3 & 17.1 \\
\hline 24 & Leptolyngbia & HS-49 & - & & 34.41 & 2.14 & & 1.3 & & 2.24 & & & & & 20.85 & 29.6 \\
\hline 25 & Westiellopsis & HS-10 & - & 1.49 & 30.69 & 3.17 & & & & & 1.58 & 22.21 & 1.99 & & 25.64 & 3.92 \\
\hline 26 & Mastigocladus & $\begin{array}{l}\text { HS- } \\
40 \mathrm{~A} \\
\end{array}$ & - & 2.32 & 38.18 & 2.11 & & & & 3.16 & 1.41 & 5.81 & 2.06 & & 11.94 & 25.5 \\
\hline 27 & Mastigocladus & HS-46 & - & & 23.41 & 2.36 & & & & 1.75 & 2.21 & 29.44 & 1.3 & & 28.61 & \\
\hline 28 & Nostoc & HS-5 & 1.25 & 4.02 & 29.37 & 3.55 & & 3.04 & & 7.05 & & & 14.14 & 3.03 & 3.38 & 5.08 \\
\hline 29 & Nostoc & HS-20 & - & 4.09 & 42.64 & 3.53 & & & & 13.31 & 1.93 & & 6.82 & 1.38 & & 9.79 \\
\hline
\end{tabular}

Table 1b. The results of the analysis of fatty acids (FAs) of the cyanobacteria strains (branched fatty acid)

\begin{tabular}{|c|c|c|c|c|c|c|c|c|c|c|c|c|c|c|}
\hline \multirow[b]{2}{*}{$\begin{array}{c}\text { Num } \\
\text { ber }\end{array}$} & \multirow[b]{2}{*}{ Genus Name } & \multirow[b]{2}{*}{$\begin{array}{l}\text { Strain } \\
\text { Code }\end{array}$} & \multicolumn{12}{|c|}{ \% Branched Fatty Acids } \\
\hline & & & $\begin{array}{c}14: 0 \\
\text { ANTE } \\
\text { ISO }\end{array}$ & $\begin{array}{l}15: 0 \\
\text { ISO }\end{array}$ & $\begin{array}{c}15: 0 \\
\text { ANTE } \\
\text { ISO }\end{array}$ & $\begin{array}{l}15: 0 \\
\text { ISO } \\
2 \mathrm{OH}\end{array}$ & $\begin{array}{l}16: 0 \\
\text { ISO }\end{array}$ & $\begin{array}{c}16: 1 \\
\text { ISO I }\end{array}$ & $\begin{array}{c}16: 0 \\
\text { ANTE } \\
\text { ISO }\end{array}$ & $\begin{array}{l}\text { 16:0 } 10 \\
\text { methyl }\end{array}$ & $\begin{array}{l}16: 0 \\
\text { ISO } \\
3 \mathrm{OH}\end{array}$ & $\begin{array}{c}17: 0 \\
\text { ANTE } \\
\text { ISO }\end{array}$ & $\begin{array}{l}17: 010 \\
\text { methyl }\end{array}$ & $\begin{array}{l}18: 0 \\
\text { ISO }\end{array}$ \\
\hline 1 & Synechococcus & HS-1 & & 6.37 & & & 1.84 & & & & 2.58 & & 6.55 & \\
\hline 2 & Synechococcus & HS-7 & & 3.87 & & & & & & & & & & \\
\hline 3 & Synechococcus & HS-8 & 4.4 & 2.69 & 1.11 & & & & & & & & 3.27 & \\
\hline 4 & Synechococcus & HS-9 & 4.52 & 2.23 & 2.86 & & 2.8 & 3.26 & & & 1.29 & & 2.68 & \\
\hline 5 & Synechococcus & HS-13 & 5.81 & 2.98 & & & & & & & 1.79 & & 3.64 & \\
\hline 6 & Synechococcus & HS-18 & 3.99 & 5.71 & 2.81 & & 2.73 & 1.22 & & 2.55 & & & 2.36 & \\
\hline 7 & Merismopedia & HS-6 & 2.97 & 2.8 & 2.86 & & 1.3 & 1.75 & & & 1.27 & & 2.28 & \\
\hline 8 & Thermosynechococcus & HS-17 & & 1.44 & & & & & & 1.29 & & 17 & 2.63 & 1.67 \\
\hline 9 & Stanieria & HS-29 & & & & 8.96 & & & & & & & 5.65 & \\
\hline 10 & Stanieria & HS-35 & & & & 9.96 & 1.14 & & & 2.68 & & & 4.96 & \\
\hline 11 & Leptolyngbia & HS-16 & & & 1.15 & 6.5 & & & 1.99 & 2.88 & & & 3.35 & 8.59 \\
\hline 12 & Leptolyngbia & HS-27 & & & & & & & & 4.17 & & & 3.98 & \\
\hline 13 & Leptolyngbia & HS-28 & & & & & 1.05 & & & 1.98 & & & 4.61 & \\
\hline 14 & Leptolyngbia & $\begin{array}{l}\text { HS- } \\
30 \mathrm{~A} \\
\end{array}$ & & & & 3.67 & & & & 6.06 & & & & \\
\hline 15 & Leptolyngbia & $\begin{array}{l}\text { HS- } \\
31 \mathrm{~A}\end{array}$ & & & & & 1.02 & & & 2.56 & & & 6.52 & \\
\hline 16 & Leptolyngbia & HS-33 & & & & & & & & 3.08 & & & 3.59 & \\
\hline 17 & Leptolyngbia & HS-34 & & 1.87 & & & & & & & 1.24 & & 2.58 & \\
\hline 18 & Leptolyngbia & HS-36 & 3.04 & & & & 3.5 & & & 5.41 & & & 3.35 & \\
\hline 19 & Leptolyngbia & HS-39 & & 3.2 & & & 1.12 & & & & & & 2.14 & \\
\hline 20 & Leptolyngbia & $\begin{array}{l}\text { HS- } \\
\text { 40B } \\
\end{array}$ & & 1.17 & & & & & & 3.17 & & & 3.75 & \\
\hline 21 & Leptolyngbia & $\begin{array}{l}\text { HS- } \\
40 \mathrm{C}\end{array}$ & & 2.07 & & & & & & & & & 2.34 & \\
\hline 22 & Leptolyngbia & HS-41 & & & & & & & & 2.15 & & & 3.62 & \\
\hline 23 & Leptolyngbia & HS-42 & & & & & 1.5 & & & 3.13 & & & 3.93 & \\
\hline 24 & Leptolyngbia & HS-49 & & & & & & & 2.45 & 2.68 & & & 4.33 & \\
\hline 25 & Westiellopsis & HS-10 & & & & & & & & & 1.36 & & 3.54 & \\
\hline 26 & Mastigocladus & $\begin{array}{l}\text { HS- } \\
40 \mathrm{~A} \\
\end{array}$ & & 1.64 & & & & & & 1.38 & & & 3.21 & \\
\hline 27 & Mastigocladus & HS-46 & & & 1.63 & & & & & 1.29 & 2.04 & & 4.74 & \\
\hline 28 & Nostoc & HS-5 & & 3.48 & 2.26 & & 1.2 & & & & 2.06 & & 4.84 & \\
\hline 29 & Nostoc & HS-20 & & 1.39 & 1.43 & & & & & 1.58 & 2.67 & & 7.1 & \\
\hline
\end{tabular}


Table 1c. The results of the analysis of fatty acids (FAs) of the cyanobacteria strains (hydroxy-substituted fatty acids)

\begin{tabular}{|c|c|c|c|c|c|c|c|c|c|c|}
\hline \multirow{2}{*}{$\begin{array}{c}\text { Num } \\
\text { ber }\end{array}$} & \multirow{2}{*}{ Genus Name } & \multirow{2}{*}{$\begin{array}{l}\text { Strain } \\
\text { Code }\end{array}$} & \multicolumn{8}{|c|}{$\%$ Hydroxy-substituted fatty acids } \\
\hline & & & $\begin{array}{l}13: 0 \\
2 \mathrm{OH}\end{array}$ & $\begin{array}{l}14: 0 \\
2 \mathrm{OH}\end{array}$ & $\begin{array}{l}14: 0 \\
3 \mathrm{OH}\end{array}$ & $\begin{array}{l}15: 0 \\
2 \mathrm{OH}\end{array}$ & $\begin{array}{l}16: 0 \\
2 \mathrm{OH}\end{array}$ & $\begin{array}{l}16: 0 \\
3 \mathrm{OH}\end{array}$ & $\begin{array}{l}17: 0 \\
2 \mathrm{OH}\end{array}$ & $\begin{array}{l}18: 0 \\
2 \mathrm{OH}\end{array}$ \\
\hline 1 & Synechococcus & HS-1 & & 1.64 & 2.27 & 1.14 & & 2.53 & 1.1 & \\
\hline 2 & Synechococcus & HS-7 & & & & & & 3.69 & 1.46 & \\
\hline 3 & Synechococcus & HS-8 & & & & 1.16 & & 3.38 & 1.56 & \\
\hline 4 & Synechococcus & HS-9 & & & & 1.73 & & 7.75 & 2.6 & \\
\hline 5 & Synechococcus & HS-13 & & & & 1.61 & & 3.59 & 1.87 & \\
\hline 6 & Synechococcus & HS-18 & & & & & & 2.91 & & \\
\hline 7 & Merismopedia & HS-6 & & & & 1.26 & & 5.46 & 1.86 & \\
\hline 8 & Thermosynechococcus & HS-17 & & & & & & 3.46 & & \\
\hline 9 & Stanieria & HS-29 & & & & & & & & \\
\hline 10 & Stanieria & HS-35 & & 1.85 & & & & 5.96 & & \\
\hline 11 & Leptolyngbia & HS-16 & & 1.18 & & & 1.56 & & & \\
\hline 12 & Leptolyngbia & HS-27 & & & & & & & & \\
\hline 13 & Leptolyngbia & HS-28 & & & & & & & & \\
\hline 14 & Leptolyngbia & HS-30A & & & & & & & & \\
\hline 15 & Leptolyngbia & HS-31A & & & & & & & & \\
\hline 16 & Leptolyngbia & HS-33 & & & & 1.9 & & & & \\
\hline 17 & Leptolyngbia & HS-34 & & 3.8 & & & 1.92 & 2.24 & & \\
\hline 18 & Leptolyngbia & HS-36 & & & & & & & & 1.19 \\
\hline 19 & Leptolyngbia & HS-39 & & & & & & 1.78 & & \\
\hline 20 & Leptolyngbia & HS-40B & 2.46 & & & & & & & \\
\hline 21 & Leptolyngbia & HS-40C & & & & & & & & 1.13 \\
\hline 22 & Leptolyngbia & HS-41 & & & & 2.67 & & & & \\
\hline 23 & Leptolyngbia & HS-42 & & & & 3.08 & & & & \\
\hline 24 & Leptolyngbia & HS-49 & & & & & & & & \\
\hline 25 & Westiellopsis & HS-10 & & & & & & & & \\
\hline 26 & Mastigocladus & HS-40A & & & 1.33 & & & & & \\
\hline 27 & Mastigocladus & HS-46 & 1.2 & & & & & & & \\
\hline 28 & Nostoc & HS-5 & & 1.56 & 2.02 & & & 4.33 & & 1.14 \\
\hline 29 & Nostoc & HS-20 & & & & & & 2.36 & & \\
\hline
\end{tabular}

Table 2. The results of the analysis of total fatty acids (FAs) of the cyanobacteria strains

\begin{tabular}{|c|c|c|c|c|c|c|c|}
\hline \multirow[b]{2}{*}{ Number } & \multirow[b]{2}{*}{ Genus Name } & \multirow[b]{2}{*}{$\begin{array}{l}\text { Strain } \\
\text { Code }\end{array}$} & \multicolumn{5}{|c|}{ \% Total Fatty Acids } \\
\hline & & & Saturated & Monounsaturated & Polyunsaturated & Branched & $\begin{array}{l}\text { Hydroxy- } \\
\text { substituted }\end{array}$ \\
\hline 1 & Synechococcus & HS-1 & 40.73 & 29.34 & 0 & 21.25 & 8.68 \\
\hline 2 & Synechococcus & HS-7 & 43.04 & 38.28 & 7.24 & 6.28 & 5.15 \\
\hline 3 & Synechococcus & HS-8 & 46 & 36.42 & 0 & 11.47 & 6.1 \\
\hline 4 & Synechococcus & HS-9 & 46.43 & 7.58 & 0 & 19.64 & 12.08 \\
\hline 5 & Synechococcus & HS-13 & 45.59 & 33.6 & 0 & 14.22 & 7.04 \\
\hline 6 & Synechococcus & HS-18 & 43.51 & 26.37 & 0 & 22.52 & 2.91 \\
\hline 7 & Merismopedia & HS-6 & 46.89 & 33.24 & 0 & 15.23 & 8.58 \\
\hline 8 & Thermosynechococcus & HS-17 & 38.61 & 49.19 & 0 & 8.73 & 3.36 \\
\hline 9 & Stanieria & HS-29 & 32.15 & 53.24 & 0 & 14.61 & 0 \\
\hline 10 & Stanieria & HS-35 & 28.11 & 43.49 & 0 & 17.45 & 7.81 \\
\hline 11 & Leptolyngbia & HS-16 & 40.56 & 31.04 & 0 & 25.67 & 2.74 \\
\hline 12 & Leptolyngbia & HS-27 & 38.61 & 53.24 & 0 & 8.15 & 0 \\
\hline 13 & Leptolyngbia & HS-28 & 39.69 & 32.5 & 19 & 4.2 & 0 \\
\hline 14 & Leptolyngbia & HS-30A & 37.62 & 36.13 & 16.72 & 9.73 & 0 \\
\hline 15 & Leptolyngbia & HS-31A & 39.93 & 30.76 & 19.22 & 10.1 & 0 \\
\hline 16 & Leptolyngbia & HS-33 & 39.49 & 28.43 & 23.52 & 6.67 & 1.9 \\
\hline 17 & Leptolyngbia & HS-34 & 32.81 & 50.56 & 0 & 5.69 & 7.96 \\
\hline 18 & Leptolyngbia & HS-36 & 31.31 & 40.13 & 9.74 & 17.64 & 1.19 \\
\hline 19 & Leptolyngbia & HS-39 & 39.02 & 32.78 & 15.49 & 5.34 & 1.78 \\
\hline 20 & Leptolyngbia & HS-40B & 33.08 & 48.22 & 6.38 & 8.09 & 2.46 \\
\hline 21 & Leptolyngbia & HS-40C & 40.1 & 37.97 & 15.29 & 4.41 & 1.13 \\
\hline 22 & Leptolyngbia & HS-41 & 34.73 & 53.85 & 0 & 6.89 & 2.67 \\
\hline 23 & Leptolyngbia & HS-42 & 28.24 & 31.59 & 17.06 & 8.56 & 3.08 \\
\hline 24 & Leptolyngbia & HS-49 & 37.85 & 23.09 & 29.62 & 9.46 & 0 \\
\hline 25 & Westiellopsis & HS-10 & 35.35 & 51.42 & 3.92 & 4.9 & 1.53 \\
\hline 26 & Mastigocladus & HS-40A & 42.61 & 24.38 & 25.45 & 6.23 & 1.33 \\
\hline 27 & Mastigocladus & HS-46 & 25.77 & 63.31 & 0 & 9.7 & 1.2 \\
\hline 28 & Nostoc & HS-5 & 41.23 & 27.6 & 5.08 & 15.21 & 9.05 \\
\hline 29 & Nostoc & HS-20 & 50.56 & 23.44 & 9.79 & 14.17 & 2.36 \\
\hline
\end{tabular}


A group of Synechococcus and Merismopedia was like the strains cluster 1 of Kenyon system, 1972. Strain cluster 1 [20] comprised rod-shaped (coccoid) unicellular cyanobacteria of the genus Synechococcus containing monounsaturated (16:1 and 18:1). The hot spring strain of Synechococcus and Merismopedia also had monounsaturated $16: 1$ (ranged 9.61 to $32.39 \%$ ), and 18:1 (ranged 2.11 to $15.82 \%$ ). In addition to a low concentration of total PUPA and its contained monounsaturated (16:1 and 18:1), all strains of hot spring (Synechococcus, Merismopedia and Thermosynechococcus) had branched fatty acids 15:0 ISO (ranging from 1.44 to $6.37 \%$ ) and hydroxylsubstituted $16: 03 \mathrm{OH}$ (ranging 2.53 to $7.75 \%$ ) which had been described above.

On the other hand, strains of hot spring filamentous cyanobacteria did not show specific groupings as well as the grouping system of Kenyon and Stanier 1972. This was likely due to the data of hot spring strains that exists only in di-unsaturated fatty acid (especially 18:2), while the Kenyon and Stanier system (1972) using Triunsaturated fatty acids (especially 18:3) and Tetraunsaturated fatty acids (especially 18:4) as distinguishing characteristics among filamentous cyanobacteria [21].

In this study, it could only differentiate between unicellular coccoid cyanobacteria (genus Synechococcus, Merismopedia, Thermosynechococcus, and Stanieria) with filamentous cyanobacteria (genus Leptolyngbia, Westiellopsis, Mastigocladus, and Nostoc) based on total polyunsaturated. In the Table 2 , it shows that the total PUPA in the group of unicellular cyanobacteria strains coccoid lower than in the group of strains of filamentous cyanobacteria. Table 2 showed the total of each type of fatty acid.

\section{Conclusions}

The research showed that fatty acids were analyzed from 29 strains of Indonesian indigenous cyanobacteria are vary widely and independent of the genus cyanobacteria. The same genus may not necessarily have the same fatty acids. All strains have saturated fatty acids of 16: 0 [hexadecanoic acid/Palmitic acid]. Almost all strains have branched fatty acids, which are 17: 010 methyl [10-Methylheptadecanoic acid]. The content of substituted hydroxy fatty acids varies and not all strains have these fatty acids.

This work was funded by Hibah Publikasi International Terindeks untuk Tugas Akhir Mahasiswa (Hibah PITTA) Tahun Anggaran 2018 to Nining Betawati Prihantini, grant no. 2288/UN2.R3.1/HKP05.00/2018. Authors thank to the Center of Excellence for Indigenous Biological Resources-Genome Studies, Universitas Indonesia, Depok for the facilities provided.

\section{References}

1. R.K. Saluja, V. Kumar, E. Sham, Renewable and Sustainable Energy Reviews, Vol 62 (2016)
2. L.E. Graham, L.W. Wilcox, Algae (Prentice Hall,Upper Saddle River, 2000)

3. M. Sachlan, Planktonologi (Universitas Diponegoro, Semarang 1982)

4. D.F. Welch, Clinical Microbiology Review 4 (1991)

5. T. M. Embley, R. Wait, In M. Goodfellow, A. G. O'Donnell (eds.), Chemical Methods in Prokaryotic Systematics (Chichester, Wiley, 1994

6. R. Li, A. Yokota, J. Sugiyama, M. Watanabe, M. Hiroki, M. M. Watanabe, Phycological Research 46 (1998)

7. R. W. Holton, H. H. Blecker, T. S. Stevens, Science 160 (1968)

8. C. N. Kenyon, R. Y. Stanier, Nature 227 (1970)

9. N.B. Prihantini, Proceeding of Limnology National Seminar2002, Bogor (2002)

10. N.B. Prihantini, D. Hendrayanti, Y. Ariyani, Sains Indonesia, FMIPA UI, Vol. 9. (2005)

11. N.B. Prihantini, W. Wardhana, A. Widyawan Y. Ariyani, Sains Indonesia, FMIPA UI, Depok (2007)

12. N.B. Prihantini, W. Wardhana, A. Wiryawan, R. Rianto, Prosiding Seminar Nasional Limnologi 2006, Jakarta (2006)

13. N.B. Prihantini, W. Wardhana, D. Hendrayanti, A. Widyawan, Y. Ariyani, R. rianto. Makara UI, Depok (2008)

14. N.B. Prihantini, A Oetari, E. Saefuddin. Laporan Hasil Riset Hibah Penelitian Strategis Nasional Tahun 2009 (2009)

15. N.B. Prihantini, W. Sjamsuridzal, A. Yokota, Proceeding ISISM 2012 (2012)

16. N.B. Prihantini, W. Wardhana, Proceedings of International Symposium on Current Progress in Mathematics and Science (ISCPMS 2015) (2016)

17. NIES-collection. List of strains: Microalgae and protozoa 7th ed. Nissei Eblo Co., Ltd. Tsukuba (2007)

18. H.C. Bold, M.J. Wynne. Introduction to the algae structure and reproduction. (Prentice-Hall, Inc., Englewood Cliffs, New Jersey 1985)

19. L.Voloshko, J. Kopecky, T. Safronova, A. Pljusch, N. Titova, P. Hrouzek, V. Drabkova, Estonian Journal of Ecology 57, 2 (2008)

20. C. N. Kenyon, J. Bact. 109: 827--834. (1972)

21. C.N. Kenyon, R. Rippka, R.Y. Stanier, Arch. Microbiol. 83 (1972) 